\title{
THE USE OF SITE IN FOREST MANAGEMENT ${ }^{1}$ BY G. ANGUS HILLS
}

\author{
G. A. HILLS
}

The author received practical experience in forestry when be bomesteaded in Northern Ontario. Living in a Scandinavian community', be learned at first band the combined busbandry of field and forest. After graduating from the Ontario Agricultural College, where be specialized in soils, be beld the position of Senior Soil Surveyor for the Dominion Department of Agriculture until 1944. During this time be received a master of science degree in chemistry, and is now finalizing a thesis dealing with land use in Northern Ontario to meet the requirements of a Pb.D. degree in geograpby. His present position is Chief Soil Specialist and Officer-in-Charge of the Silviculture and Soil Section of the Research Division of the Ontario Department of Lands and Forests. .He is chairman of the Standing Committee of Soils and Site of the Canadian Institute of Forestry. He bas been recently engaged to lecture part-time in Forest Soil Ecology at the Forestry Faculty, University of Toronto.

\section{ABSTRACT}

Total site is that combination of environmental features with which the forest manager must deal in the growing and barvesting of forest crops. It is not enough to know the kind of regional climate, the zonal soil type and the regional cover type. The forester must know the significant features of each local area with which he has to deal.

It is essential to know the variations in soil profile and forest communities at every stage in forest succession for each specific landform and climatic region. It is also necessary to know the effect of man's activities upon forest succession and soil characteristics. For the actual management of any specific forest area, a forester requires a knowledge of total site, not merely a classification of site.

It is hoped that the proposed site classification may provide a scientific regional framework into which may be placed those significant site features with which a practicing forester must deal. The objectives of this site classification are twofold:

1. To provide a systematic approach to forest description and site evaluation of local areas.

2. To provide a framework to facilitate the application of results of forest research and practice to other areas.

\section{THe HOLISTIC APPROACH}

Forest management is the art of producing forests and forest products by applying to an area of land the principles and techniques of silviculture, engineering, science and business. A knowledge of cutting systems, airphoto interpretation, soil formation, forest succession and economic theory, in fact all knowledge, must be actually used for the production of forests on a

1 Presented to the joint meeting of the C.I.F.-S.A.F. in Montreal, November, 1952 2 Chief Soil Specialist, Ontario Department of Lands and Forests, Maple, Ontario. 
specific area before it can be considered forestry. Forest production depends upon specific combinations of the capabilities of the land, the potentialities of the forest which grows upon that land, and the ability of the man who manages both forest and land. It is not enough to know the general effect of a certain soil feature upon forest growth, rather it is essential to know what specific effect can be expected when that soil feature is found within a specific unit of the forest environment. This means that there must be a consideration of all the interrelationships of all the features which determine production upon a given area. The forest environment is an integrated combination of soil, climate and forest, existing either in a natural state or in a form which has been modified by man. Each unit of a man-modified environment is a specific example of the effect of social, economic and technological controls upon the adjustment which a forest community must make to local combinations of soil and climate. If the forest environment is broadly conceived as an integrated system of physiographic (i.e. soil and climate) and biotic features, in other words a system which embodies both the forest and the forester, then forest management becomes the manipulation of environment. Without an intimate knowledge of total environment we can exploit the forest, but we cannot manage it.

The classification and naming of environmental units are but secondary considerations when compared with the necessity of actually becoming familiar with the environment of a management unit. In fact, for centuries the husbandry of field and of forest has been carried on by men who did not possess the ability to separate and classify the environmental features which they manipulated as a whole, nor could they convey, by words alone, the procedures which they used in growing the crop. As the old Scot said about some of his experiences, "It is something which is more easily felt than tell't". In fact it cannot be "tell't" unless it is "felt". In American the extensive nature of our forestry necessitates that the environment which is "felt" becomes an environment which is "tell't", and teams of forest husbandmen and scientists must satisfy this desperate need. Over broad areas a successful utilization of the many intellectual and technical tools at our disposal, for example, survey techniques, logging logistics, economic theories, experimental methods, geographic principles, hypotheses of soil formation and theories of plant metabolism, requires an environmental framework which can be recognized and described. The intricate interrelationships within the units of this featureframework makes it difficult to describe them adequately; however simple tagnames have been found useful when care is exercised in their interpretation.

The complex of all the environmental features of a prescribed area is called "total site" in order to differentiate it from more restricted concepts. Total site has the same connotation as the site defined by the Committee of Forest Terminology, Society of American Foresters, 1950, providing certain interpretations can be made. Total site can be defined as "an area considered as to its ecological factors with reference to capacity to produce forests or other vegetation" if it is acknowledged there is no feature without ecological significance, the effect being positive, negative or neutral. Total site may also 
be defined as "the combination of biotic, climatic and soil conditions of an area" if it is agreed that all features may be included. Site index is what the term signifies, an index of site, but it is not site.

The general approach used in the classification of total site is based on the principle that, although site includes all environmental features, it may be classified by a single group of features or by any combination of featuregroups which are considered significant in the production of forests. For universal use, it is advantageous that a standard frame of reference features be established by following a definite sequence of differentiation. For "ad hoc" classifications the process of increasing the detail employed may follow any order, for example, if the combination of standard reference features do not differentiate sites sufficiently, the classification may be extended using those features which would appear to be best for the purpose. In fact, it is possible that a combination of the universal and ad hoc scales will be required to serve most adequately the needs of the practicing forester. Combining the two systems of classification usually involves adjustments which may attain considerable magnitude if the ad hoc classification has not been conceived initially as a facet in a total site classification.

The three features which have been chosen to constitute the universal frame of reference are (a) ecoclimate (local climate), (b) soil moisture and (c) soil nutrients. Each of these is actually a group of features composed of a great number of basic factors, most of which are too small to be detected either by the human senses or by the most delicate instruments. However, features which reflect the effective combinations of these factors may be recognized in the field by the practicing forester with a minimum use of scientific instruments. Pore pattern, which is the effective combination of the texture and structure of soil and geologic materials, is used to indicate potential soil moisture within each local region. The actual soil moisture available in any given combination of texture and structure is determined generally by the type of soil profile development including the formation of glei, or water-saturated horizons within ten feet of the surface. Specific combinations of slope and pore patterns used in conjunction with profile development gives a very reliable picture of available moisture. The absolute amount for each combination of slope and pore pattern will vary with regional climate. Associated with this change in climate will be a change in vegetation and a concomitant change in soil profile.

Orderliness of classification may be assured by placing the levels or intensities of any feature within a scale ranging from one extreme to the other. The scale may be either universal or local. The universal scale provides for all levels wherever they may be found. In the case of the local scale the region or other local level of application should be clearly defined.

The scale is a complete continuum whose extremes have either been located in nature or have been theoretically established. All intermediate categories 


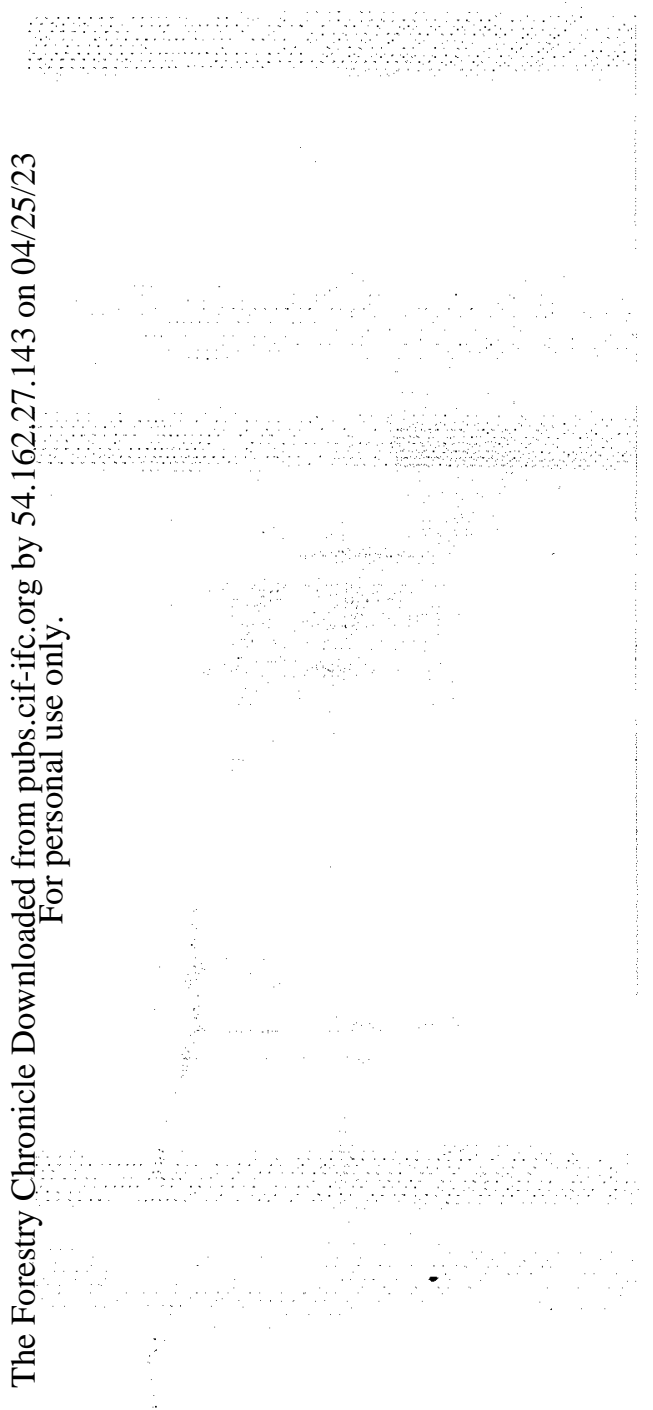

must be included whether they have been located or not. To find them in nature facilitates the division of the continuum into natural ecological units.

It is advantageous to divide the scale into an uneven number of categories so that there will be an equal number on either side of the middle. For the purpose of shorthand recording on maps and elsewhere, the classes of each scale are designated within a single digit so that a decimal symbol may be established with the classes of each feature occupying a definite position in the decimal system. Arabic numerals may be used if the classes required are few in number. It has been found convenient to establish eleven classes using the ten numberals 0 to 9 and placing the Greek letter theta before the 0 to form the eleventh digit. This provides for five places on each side of the middle category. It also provides for simple groupings.

To classify total site we must classify the whole both as a whole and as a complex of parts describing the characteristics of the parts and the type of relationships of the parts to one another and to the whole. When we classify sites upon their inherent natural qualities such as "site with a humid local climate", "sites with a moderate soil moisture regime" or "site with a low soil nutrient regime", we are classifying a whole by its parts. When we classify sites by their actual production of a specific crop under a specific method of management, we are classifying a whole by a characteristic of the whole. In fact, it is possible that two wholes made up of parts which are widely different may be placed in the same class in so far as some phase of forest production is concerned. With respect to this aspect of their nature, they are similar wholes although the parts may differ radically. It must be recognized that the difference in the relative capacity of two sites as wholes for the production of forests will depend upon the type of evaluation employed, whether it involves the capacity to facilitate the establishment of a stand, or to promote growth after the stand has been established.

This approach to site as an integrated whole of many inter-related parts is called bolistic from the Greek word "holos" meaning whole, W-H-O-L-E.

\section{The Procedure in Site Classification}

Since site can be classified only by working on the area, it is necessary that the forest manager lives with the forest. Whether he initiates his work by making a broad reconnaissance survey of the area in general or a detailed survey of his management unit, will depend upon what information is available for the area, derived from both forestry and the natural sciences. Scientific knowledge and techniques which constitute the tools required by the forester in classifying and mapping sites in an area include the following:

1. Surface relief.

2. Bedrock relief.

3. Geologic materials (to a depth of at least ten feet) :

(a) texture

(b) fabric (or structure)

(c) petrography (including that of the bedrock if within rooting distance) 
4. Underground water.

5. Soil profile types, their formation and horizon characteristics.

6. The silvical characteristics of the forest and ground vegetation.

7. The plant sociology and vegetative succession of the area:

(a) in natural stands

(b) in logged over stands

(c) in managed stands

8. Stand histories:
(a) fire
(b) logging history
(c) disease attacks
(d) insect attacks
(e) wind damage

9. Photo interpretation of aerial features (including the following):

(a) vegetative cover

(b) slope patterns

(c) stream and lake patterns

(d) erosion and deposition patterns

(e) cultural patterns:

(i) cultivated fields

(ii) abandoned farm land and old field timber stands

(iii) logged over stands

(iv) plantations, etc.

The value of information obtained by workers in the natural sciences depends upon the intensity of the field observations and the detail of the written records particularly those aspects useful in site evaluation. The practicing forester should be equipped with "experience" in recognizing geologic formations, soil types, vegetation associations and the like, rather than depending too heavily on the vague generalizations of some specialist. Even though these other scientists have presented their particular phenomena in minute detail, the forester must integrate his findings into a total site for each local area.

In the past, sites have been classified by ground vegetation, forest cover, climatic soil types, single soil characteristics, landform and other features. No single feature or feature-group can in itself adequately define site. Ground vegetation types are not adequate unless they are considered in relation to forest cover types, stand history, regional climate, local relief and so on. There is little doubt that Cajander, the founder of the forest site type school, and some of his followers, Heimburger for example, have used a broader base than their nomenclature of ground vegetation would indicate. In general, however, the 
value of these classifications has been greatly reduced through the failure to relate adequately plant associations to physical setting. Similarly, climatic soil types such as podsol, grey brown podsolic, etc., are of little use unless they are tied into the particular physiographic and biologic niche which they occupy in a well-defined regional pattern.

The establishment of a regional site pattern is the first project in any area. Although this cannot be completed without detailed studies of local physiographic and biologic niches, the early organization of detailed studies within a regional framework expedites the completion of both regional and local studies. Forest site regions are areas in which there is a fairly definite relationship of vegetation characteristics to established physiographic classes. Within each site region, each physiographic class expresses a definite and fairly narrow range in soil and vegetation characteristics. The range in vegetation on each physiographic site is dependent upon a combination of such factors as chance, vegetation succession, as controlled by plant competition and damage from fire, insects, disease, wind, animals and man.

The regional site pattern is established by working from a normal reference site. A normal reference site has normal relief defined as gently rolling with slopes of say three to ten percent, which are not located on exposed ridges or sheltered pockets. A normal reference site is one with normal pore pattern stated to be that of a heavy loam or clay loam of such a structure that available soil moisture will be retained without excess amounts of gravity water in a region of moderate rainfall. A normal reference site is one with moderate potential for the release of available plant nutrient, being neither low in the commonly recognized nutrient elements nor too high in those elements considered to be toxic such as calcium, carbonate, iron etc. Wherever normal reference sites are to be found, the inter-relationships of physiography-crop-man are recognized in order to establish the following: (a) the trends in natural succession on these sites, (b) the type of soil development which is associated with such vegetation changes and, (c) the effect of silvicultural changes in relation to specific cover types and soil profile types.

After establishing the physiography-crop-man relationships on the normal sites, the forester must consider deviations from the normal along as many dimensions as are necessary to satisfactorily differentiate the sites for management. He must look upon the normal as the point at which many spectra intersect. The first series of spectra to be considered are based on physiographic reference features and include the following: (a) changes in the vegetation spectrum which reflect changes in local climate, from the extremes of the hottest to the coldest, and from the most humid to the driest for a particular region, (b) changes in the vegetation spectrum reflecting changes in soil moisture, from the driest sites to the ones with water-saturated surface, (c) changes in the vegetation spectrum reflecting changes in soil nutrient regime from the sites with extremely low nutrient levels through the normal, where the highest balanced conditions occur, to the other extreme where high 
concentrations of nutrient elements and of other toxic elements reach lethal proportions.

The forester should now re-examine the forest succession spectra along these three physiographic dimensions and note the deflections in succession which are associated with fire, logging, insect attack, disease, wild animal damage, wind damage and silvicultural treatments.

The forester has now a regional mosaic which he can use to compare his region with other regions. For instance, in Ontario the presence or absence of white spruce does not characterize regions, for it is found in all regions. However, these regions are characterized by where and when it is found-in what particular region, on what physiographic sites, and in what stages of succession.

To know inter-regional relationships is advantageous to the forester, for a knowledge of these enables him to introduce the experimental findings and silvicultural experience from other regions. Regionalized knowledge provides a comparable basis for inventory and management planning, as it indicates the exact position which production of a specific species occupies in relation to production elsewhere.

However, in order to manage a crop, the forester must do more than establish regional patterns. He must consider local areas in detail. On each of the physiographic site classes there may be considerable variation, reflecting stand history, which becomes evident not only in the stand, but in the ground cover and soil profile. Many of these differences in single features of soil or vegetation have been used successfully within relatively local areas. The single features which some workers have found satisfactory do not work so well in other areas. In order that a single feature classification may be applied, the total effectivity of all the other features in the complex must be approximately the same. For example, soil moisture will differentiate site very well, within a local area, providing that the regional climate remains relatively uniform, and that there is no extreme differences in topography or chemical composition of geologic and soil materials. If relief varies considerably in short distances, it may be necessary to introduce ecoclimate into the classification. If petrography changes considerably, then a nutrient regime scale may be needed. Generally these are required, not to replace the moisture regime scale, but in addition to it. The significance of soil features such as the $\mathrm{pH}$ of the various horizons, the depth and type of humus layers, etc., can be interpreted with greater accuracy if placed within the framework of regional climate and local physiography. The forester, in determining the potentialities of local sites, must use the regional physiographic framework and superimpose upon it an ad hoc classification as the need becomes evident. It is perhaps a mistake to suggest that the additional data is required to meet a classificatory need. Classification can be justified on one basis only, and that is its function in forest management. It will be found that site knowledge required for forest management will exceed the suggested requirement for classification. The greater the 
amount of information which is organized within the regional framework, the easier the management of the forest will be. Some prefer to call this forest description rather than site classification. The name is not important. What does matter is the consideration of the whole, i.e. the forest and its environment. Site classification is a means of comparing wholes in an organized way.

\section{The Procedure in Site Evaluation}

It is not enough for the forester to know thoroughly the forest environment which he is to manage. He must organize this knowledge on the basis of crop production, considering such matters as sustained yields, crop rotations, regeneration and establishment, improvement cuttings, etc. The complex units of the natural environment must be interpreted in relation to these problems in such terms as merchantable volume per acre, height of dominant and codominant trees at a given age, ease of stand establishment under varying conditions of natural competition and management practices, and ease of logging. The forester must rate the sites on his area in terms of use-capability. These ratings may be solely for forestry, but in many cases forestry must be integrated with other uses such as game management, and in some cases with farm management. Fortunately the classification of site by its natural qualities provides a basis for all land use. From among the many forest uses to which each locality may be put, the forester must choose the one he would recommend, and see that all these fit into a well integrated plan for the whole management unit.

Forest use-capability is a classification of the potential of land to produce forests, and use-capability classes are designed to indicate not only what crop may be produced, but also its volume and quality and the time and specific methods of management required for specific site conditions.

Seldom does a single use-capability class cover all the above points. However, a site is not fully classified until there is a rating for the production of every probable crop under every promising cultural method, stating the length of rotation as well as the yield and quality which such combinations of culture and site will produce.

It is apparent that there may be few or many use-capability classes for each physiographic site. Some of these classifications will indicate a high potential for some crops and others will indicate a low potential for other crops. Some will be generalized, others will be specific depending upon the use of the classification and the knowledge at hand.

Use-capability classes may be defined in absolute terms (board feet per acre), or in comparative terms (excellent, poor, etc.). Usually, it is convenient to establish a comparative system of rating for all regions and to define, in absolute terms, these comparative ratings for each specific region.

\section{CONCLUSION}

The art of forestry in America is very young. Only in a few places in the United States, and in still fewer places in Canada, do we find managed forests. In order to profit from the experiences of forest managers, both in this coun- 
try and in Europe, we must know our environment thoroughly. We must begin to practice the art by getting acquainted with our environment before we attempt to integrate the findings of others into our management program. The practitioner of the art of forestry must have an intimate knowledge of total site in order to visualize all the chain reactions which may be set up when a certain treatment is introduced. He must be well acquainted with the stages and trends in plant succession which may occur on each physiographic site, and with the manner in which introduced species will fit into this scheme. He must anticipate the soil changes which will occur. He must know the level of resistance to disease and insect attack which the plant cover on this site may have. He must have a fairly good idea of the quantity of the timber which will be produced. In brief, he must have intimate knowledge of total site to determine what methods to use in bringing about the change. A major difficulty is that the sites on which results have been obtained have not been adequately described in the past. The European forester is well acquainted with his environment, but in common with farmers in general, he does not know how to describe it.

There is much we do not know about silvicultural methods and their application to local areas. It will be the task of the forest research worker to determine basic relationships within the framework of total site. However, it is possible to commence the practice of silviculture today, providing there is a close liaison between the science, the business and the art of forestry. There is no time for one specialist to wait upon another, so great is the need for the actual practice of silviculture in our forests. The concept of total site should provide a strong link in a co-ordinated program in which there is an active participation on the part of every forester towards the common goal of well managed forests. 